\title{
A case study of students' perception of goal setting as a tool for learning
}

\author{
Helga Grant \\ Adult literacy tutor with Literacy Waikato
}

\begin{abstract}
This paper discusses the feelings and perceptions of a group of Year 3-6 students regarding the usefulness of goal setting as a tool for enhancing their learning. The project adopted a case study approach which involved the researcher as an interviewer and observer. Data were collected through interviews, an observation and document analysis. Students were found to have positive perceptions about goal setting as a tool for helping their learning. Their perceptions appear to be a result of how this has been implemented in their school, particularly the level of autonomy they have in selecting personal goals and the focus on mastery learning.

\section{KEYWORDS:}

Goals, educational objectives, self-management, learning.

\section{INTRODUCTION}

Browsing through the principles in the New Zealand Curriculum Framework (NZCF) one will come across the following statements: "Students will be encouraged to become independent lifelong learners" through the "development of the knowledge, understanding, skills and attitudes that will empower students to take increasing responsibility for their own learning" (Ministry of Education, 1993, p. 7). Continue further to the essential skills and one will read: "students will set, evaluate and achieve realistic personal goals" (p. 19). Bold statements - but what do they mean for teaching and how can they be achieved? Further, what do they mean for primary aged students who are beginning their journey of formal learning, and how can these principles be taught in a way that is meaningful and relevant to them? Finally, what do students think of these efforts to help them become independent lifelong learners? These questions provide the basis for this study.

One endeavour to bring to life the principles in the NZCF has been undertaken by a primary school in the upper North Island. Situated in a small town, this school has a strong learning culture with an emphasis on personal empowerment for lifelong learning. The school's goal setting programme is guided by two statements in their core values:

1 Valuing learning.

2 Accepting responsibility for one's own learning and actions. In addition, a core belief that "responding positively to changes in society and adaptation to new innovations is critical to the future development and success of our school" provides the basis for this school's goal setting programme, which was implemented school wide at the beginning of 2004. This study looks briefly at this programme and explores the value of goal setting as a tool for learning from the perspectives of the students.

\section{WHAT DOES THE LITERATURE SAY?}

\section{Goal setting as a component of self-regulated learning}

Preparing students for lifelong learning requires an understanding of the qualities and skills they need in order to become strategic, motivated and independent learners. Developing these skills and qualities enables students to take an active role in managing their own learning and behaviour and become self-regulated learners (Paris \& Paris, 2001). Self-regulated learning is defined as an "active, constructive process whereby learners set goals for their learning and then attempt to monitor, regulate and control their cognition, motivation and behaviour, guided and constrained by their goals and the contextual features in the environment" (Pintrich, 2000, p. 453). The development of self-regulated learners is regarded as the ultimate goal of contemporary teaching efforts (Brophy, 2004).

The ability to self-regulate allows students to take control of their learning (Paris \& Paris, 2001). Students who believe they can have influence over the management of their own learning are more likely to achieve success (Bandura, Barbarnelli, Caprara \& Pastorelli, 1996, cited in Schunk \& Zimmerman, 1998). In addition, self-regulated learners are more likely to view their futures optimistically (Zimmerman, 2002). This involves the use of a number of key self-regulatory processes, with the relative presence of each accounting for variances in students' level of achievement (Schunk \& Zimmerman, 1994; 1998, cited in Zimmerman, 2002).

The component skills for self-regulation include:

- setting specific proximal goals

- adopting strategies for attaining the goals

- monitoring performance for signs of progress

- restructuring the physical and social context to make them compatible with the goals

- making efficient use of time

- self-evaluating methods used to achieve the goal

- attributing results to strategies used

- adapting future methods to ensure positive outcomes.

(Zimmerman, 2002, p. 66). 


\section{The goal setting process}

Clearly, goal setting is an integral component of self-regulated learning (Schunk \& Zimmerman, 1998). The process of goal setting has a number of phases, each of which are required for the successful attainment of a goal (Pintrich \& Schunk, 2002). This begins with selecting a particular goal to be attained. A number of personal beliefs can affect goal choice including the learner's self-efficacy, goal orientations (performance or mastery) and intrinsic interest in (or valuing of) the task (Locke \& Latham, 1990; 2003).

Learners' goal orientations are important because they affect how students approach learning tasks and evaluate their achievement. Learners' goal orientations are generally divided into two categories: mastery (or learning) goals and performance goals. Learners with mastery goals are oriented toward "developing new skills, trying to understand their work, improving their level of competence, or achieving a sense of mastery based on self-referenced standards" (Ames, 1992, p. 262). In contrast, learners with performance goals tend to focus on preserving their sense of ability and selfworth by trying to outperform others (Dweck, 1999). Mastery goals should be encouraged because they promote deeper learning and self-improvement, whereas performance goals can result in superficial learning and constant comparisons to others (Stipek, 2002). Classroom contexts have been found to powerfully influence students' goal orientations, and a number of structures and instructional strategies have been recommended to support the development of mastery goals (Ames, 1992, p. 267).

Once a goal has been selected, commitment to achieving the goal is required for successful attainment. Goal commitment is demonstrated by learners' enthusiasm and determination to achieve the goal (Pintrich \& Schunk, 2002). Guiding students in setting their own goals, rather than imposing goals on them, is one of the most effective ways to increase students' goal commitment (Ridley, McCombs \& Taylor, 1994, cited in Eggen \& Kauchak, 2001). Students who are committed to their goals engage in strategic planning by selecting learning strategies or methods designed to attain the goal (Zimmerman \& Martinez-Pons, 1992, cited in Schunk \& Zimmerman, 1998).

As action is taken to achieve the goal, goal monitoring is employed. Goal monitoring involves the continual observation of progress towards the goal, and adjusting actions to ensure it is reached (Brophy, 2004; Eggen \& Kauchak, 2001). Goal monitoring is followed by some form of evaluation (self or by others) about the level of attainment in relation to the criteria or standard initially set. This may lead to the setting of further goals or adjustment of current ones to ensure they are met. Although the term goal setting is used in this study, all aspects of the goal setting process are included.

\section{Goal setting and motivation}

Goal setting is an important motivational process (Bandura, 1988, 1997, cited in Pintrich \& Schunk, 2002) because goals have a number of motivating functions. Firstly, they focus the learner by directing attention and effort toward goal relevant activities (Locke \& Latham, 2003). Secondly, their level of difficulty can energise learners, with studies finding that students invest greater effort to achieve high goals compared to low goals (Locke \& Latham, 2003). Thirdly, having goals can increase students' persistence in accomplishing tasks (Alderman, 2004; Ames, 1992).

According to Marzano (1992, cited in Walker-Tileston, 2004), "a growing body of research indicates that when students are working on goals they themselves have set, they are more motivated and efficient, and they achieve more than they do when working to meet goals set by the teacher" (p. 4). The need for goal ownership is supported by Latham, Erez and Locke (1988, cited in Locke and Latham, 2003) who found that people are more likely to view goal attainment as important when they have participated in setting the goal. However, Latham et al. (1988) also found that goals set by others can be effective when a rationale for the goal is given and understood by the learner.

\section{Characteristics of effective goals}

Research has found that that the effectiveness of goals can be increased by a number of factors. Locke and Latham (1990; 2003) describe three characteristics that are required for creating effective goals. They include goals that are specific (rather than broad and general), immediate (rather than distant) and challenging (rather than too easy or too hard).

\section{THE PROCEDURES OF THIS STUDY}

This study set out to explore students' perceptions about the usefulness of goal setting as a tool for learning. Specifically, it sought to answer the following questions.

1 What do students perceive as the usefulness of goal setting?

2 How do their perceptions correspond with the aims of the school's goal setting programme?

3 What strategies do they find useful when goal setting?

4 What do they find difficult about goal setting?

5 How does gender affect their perceptions?

The study was undertaken in a contributing primary school with approximately 350 students. Goal setting has been implemented school-wide with each syndicate adapting it to make it age appropriate for their students. At the time of the interviews, the programme had been operating for about six months. The Principal considered the programme to be still in the implementation and development stage and intended to review it at the end of 2004.

Each class uses goal setting at different levels: personal, group and whole class goals. Though these goals are used in similar ways in the two sample classes, they are implemented over different time scales. For example, in Year 3-4, personal goal setting takes place on a weekly basis. The students each choose a goal to last for a week 
and reflect on that goal daily, deciding at the end of the week whether or not they have achieved it. In contrast, students in Year 5-6 set daily personal goals, choosing from either from the class programme or written feedback from the teacher regarding previous work. The reason for this difference in frequency between middle and senior students relates to manageability. Middle school students typically take longer to write their goals than senior students and would more likely experience difficulty in selecting a new learning goal daily.

Two types of goals are used at this school: learning and behavioural. Behavioural goals were mainly used at the beginning of the year to introduce the concept of goal setting because they clearly demonstrated the different aspects of an effective goal. In addition, they provided a means by which students could begin to take responsibility for their own behaviour. At the time of the study, the middle students were being encouraged to move away from setting behavioural goals as their personal goals and use learning goals instead. Students in the senior class were already setting personal learning goals and used group behavioural goals.

The participants for this research included the Principal, two classroom Teachers (one Year 3-4 teacher and one Year 5-6 teacher) and 16 students. Four girls and four boys were interviewed from each class.

Interviews were used as the primary method of data collection in this study, as they are an ideal method for obtaining people's perceptions (Merriam, 1998). Interviews allow participants the opportunity to elaborate on their thoughts and enable researchers to probe and seek clear meaning (Berg, 2004). The principal and teachers were interviewed individually first in order to provide the context for the study and to help answer one of the main subquestions. The students were then interviewed in focus groups with four students in each group that were separated by class level and gender.

All of the interviews were conducted in a semi-structured format. The students were asked the following questions.

1. How do you use goal setting in your classroom?

2. How do you choose a particular goal?

3. What stategies do you find helpful when setting your goals?

4. How do you know when you have achieved a goal?

5. Why do you think you do goal setting?

6. Are some goals more important to you than others? Why?

7. In what ways do you think goal setting helps your learning?

8. What do you find difficult about setting goals?

9. How useful do you think goal setting is for helping you learn? Why?

All interviews were transcribed verbatim and analysed, with comments relevant to the research questions highlighted in different colours and grouped under appropriate headings to form categories. This allowed the researcher to identify emerging patterns from each interview and compare them with the others. Other additional information that emerged from the interviews was also collated and coded.

Participants' comments included in this paper will use the following codes: (Pr) for the Principal, (MT) for the Year 3-4 Teacher, (ST) for the Year 5-6 Teacher, (MG and MB) for the middle girls and boys, and (SG and SB) for the senior girls and boys.

\section{RESULTS OF THE STUDY \\ What do students perceive as the usefulness of goal setting?}

Overall, the students felt that goal setting was useful for helping their learning in different ways. All groups agreed that goal setting helped them to improve and get better at learning "They [goals] help you to achieve better things and help you to improve on your learning" (MB). "[Goals are] very useful to help us with our learning and to guide us" (SG). Goal setting helped them to keep focused. "It [goal setting] helps with my thinking and concentrating on my work" (SG). "Goals keep you focused during the day and during the task" (SB). They also agreed that goal setting was useful for later life. "Goal setting helps your learning because then you know how to set goals for when you're older" (MG). "[Goals] help us to learn and have a better future and make us feel confident" (MB).

Some of the students indicated that the usefulness of goal setting depended on the importance of their selected goal. This in turn affected the amount of effort they expended in trying to achieve it.

"If it's the same goal you just write down randomly you wouldn't achieve it because you wouldn't really care, but if it's a goal you really want to work towards you would try hard and achieve it" (SB).

In addition, the importance of a particular goal and the level of challenge it provided appeared to make a difference to the degree of satisfaction students feel when achieving their goals. Students reported feeling more pride when they obtained a goal they really wanted and experienced a greater sense of achievement when the goal was more challenging.

"The hard ones make you feel really proud because they're real hard to achieve and the easy ones are just - OK " (MB).

"If I achieve a harder goal, I feel that I can achieve a harder goal than that" (SG).

The students cited feelings of disappointment and guilt when goals were not achieved, and either attributed this to lack of effort or an unrealistic goal. Their responses usually included a resolve to try harder or to modify goals to make them more attainable.

One group cited goal setting as a way of helping them to make good decisions about their behaviour and to subsequently keep out of trouble. 
"It helps you to do better things because you're doing the right things, not making bad decisions, you're making good decisions" (MB).

"It helps you to get a good attitude, helps you to be good on the mat and helps you make any good decisions" (MB).

However, one group indicated that not all students found goal setting a valuable activity, but rather something they did because they had to.

"Some people just do it for the sake of it because their teacher told you to do it, to set a goal...so whatever the teacher says, they just go and write it down and take no notice really and say, 'Yep, that's over and done with, nothing else to worry about" (SB).

Was there agreement between the students' perceptions and the aims of their school's goal setting programme?

The overall aim of the school's goal setting programme is reflected in the school's core values of "valuing learning" and "accepting responsibility for one's own learning and actions". The idea of using goal setting was developed to make learning important for students by using formative assessment strategies such as sharing learning intentions and providing feed-forward to guide students' learning. The key purposes for implementing goal setting were outlined by the principal.

"One of the key words in our mission is to empower students. When we looked at ways we might empower students in their learning we wanted to increase responsibility and we wanted structures that would signal or focus on the learning We wanted ways of making learning important for kids" (Pr).

In addition, the Principal cited some long term aims for goal setting.

"What we are hoping for them to learn is to become more self-managing in their learning and to take more responsibility, and in the big picture - become lifelong learners. That's what this is all about, and along the way the kids' learning is a lot more focused and I think more effective and empowered" (Pr).

So, how did the students' perceptions correspond? Goal setting was seen by the students as a strategy that guides their learning.

"It's to help guide us in our learning and guide us through our learning" (SB).

"[We do goal setting] to help us with our learning and to guide us and to help us achieve a goal" (SG).

They recognised goal setting will help them in the future.

"You do it because you want to be able to set goals when you're older and achieve them, and then make them bigger and bigger and you'll make a big success" (MG).

"It helps you to reach the higher stages and go the next step in life, the next level to just help us and guide us through our life" (SG).

\section{Goal setting improves the learning process.}

"Goal setting helps your learning because you can think that - "I am good at this or I am not very good at it, now how could I do a bit more to get a bit more knowledge out of it" (MG).

Some identified goal setting as providing reasons for learning.

"It lets you know why you're actually doing the things you doing and it gives a point of why you should be doing it" (MG).

Students recognised that goal setting makes achievement easier.

"[We use goal setting] to make things we're meant to achieve, easier to achieve because we're not trying to achieve the whole thing at once" (SG).

\section{Useful strategies for setting goals}

Students use the acronym SMART (specific, measurable, achievable, realistic and timeframe) when setting goals. Each group referred to the SMART goal criteria as a strategy for helping them make specific, achievable and measurable goals. The process of helping students develop the concept of a SMART goal was described by the middle Teacher.

"We talk at the beginning of the year about what a smart goal is, like would a smart goal be 'I would like to be able to jump over the classroom' or perhaps maybe 'I'd like to jump a metre in the long jump'. So we talk about a goal that would be a sensible one that you could achieve in a week" (MT).

Students' descriptions of the goal setting process showed that they understood the concept.

"When you're doing your steps you have to make sure they're nothing to do with another goal altogether, and you have to make sure they make sense, and you have to make sure you can achieve them, and make sure they're not silly" (MG).

Other strategies identified differed between the middle and senior students. The middle students identified Teacher guidance and suggestions, and displayed learning intentions and ideas they had written in the middle of their goal setting books as useful strategies.

"When doing class goals, the whole classroom gives goals and [teacher's name] if we say, 'to be quiet', she would change it into a specific one" (MB).

"I get my ideas from the learning and teaching on top of the wall and in the middle of my book" (MB).

"In our spare time we're allowed to write in the middle of our book some ideas for goals, so I look down the list and think, what are we working on now, and then I think whether that would be a good goal to achieve in a week" (MG).

In contrast, the senior students described reusing past goals, extending a present goal, or using longer term goals (to last for a week) as useful strategies for ideas.

"Sometimes we choose ones we've done a few weeks before or something like that" (SG). 
"Sometimes if we haven't accomplished a goal we do it again" (SG).

"If you've already done the same goal before, you add a bit more on ... like on Wednesday I usually set a goal about my basketball and if I score one goal one week then for the next week I add on one more goal and if I don't get that amount I just keep with that goal for the next week" (SB).

"Sometimes you can use long term goals if you're stuck for ideas say if there's a four day sports thing, you can just have one long-term goal for playing fair and having fun"(SB).

\section{Difficulties in goal setting}

Running out of ideas was cited as the most common difficulty experienced by all of the students.

"When you have no ideas... I usually run out of ideas and I don't have any in the middle of my book and it takes me longer to have a think and sometimes I have to do it at morning tea" (MB).

For the senior students, identifying new daily goals appeared to be increasingly difficult as the year progressed. This indicated that the senior students possibly felt saturated in relation to their personal goals.

"Well it's hard when you can't think of what your goal is going to be and because we've been doing it for so long and we've put down pretty much all of the goals we can think of, it becomes hard to think of something new" (SB).

"We set goals everyday and we spend like 200 and something days at school so you've got to set like 200 goals a year and it starts becoming really hard because you run out of goals to set" (SB).

Other difficulties described by the students included writing steps for how they intended to achieve their goal, and identifying possible barriers or blocks.

"We have to do at least two steps, so sometimes it is hard to do the steps" (MG).

"It can be hard to think of the steps and blocks" (MB).

"Goals should have more than one step and that can be hard to think of" (SB).

The Teacher of the middle students observed that some of her students found it difficult to relate the steps to the goal, resulting in steps that belonged to another goal altogether. However, this difficulty may be age related as it was not mentioned by the senior Teacher or senior students.

\section{How does gender affect their perceptions?}

Age seemed to affect students' perceptions of what goal setting was all about more than gender. The senior students felt strongly that goal setting was more valuable when the goal is something they really want to achieve.

"It depends how useful the goal is. If it is a goal you really want to work towards you would try hard and achieve it, but if it's the same goal you write down randomly, then you wouldn't achieve it because you wouldn't really care" (SB).
The middle boys mainly perceived goal setting as a strategy for helping them make good decisions about their behaviour and subsequently staying out of trouble.

"It helps you to do better things because you're doing the right things, not making bad decisions you're making good decisions" (MB).

"It helps you to be good on the mat and helps you to make good decisions" (MB).

In contrast, the middle girls perceived setting goals as useful when the goal was something they had not achieved already.

"It would be silly to write a goal, like if someone kept their desk tidy 24/7 and they always cleaned it out, then their goal shouldn't be to keep their desk tidy because they've already achieved it" (MG).

"People do it because they're doing something and they want to get better at it, so the best way is to set goals and think, what can I do to help me achieve my goal, and what could try and stop me, and not let things stop you" (MG).

\section{DISCUSSION OF THE RESULTS}

The results of this research suggest that these students hold positive perceptions about the usefulness of goal setting as a tool for enhancing their learning. Three main factors are identified as possible causes for these perceptions.

First, the students can see how goal setting is positively affecting their learning by experiencing the benefits of setting and achieving a variety of goals. Because the students are personally involved in setting their own goals, they experience the satisfaction of achieving challenges they have made for themselves. This feeling of autonomy helps students to take more control over their learning, helping them develop into "independent lifelong learners" (Ministry of Education, 1997, p. 7). This finding supports Brophy's (2004) assertion that students need to be actively involved in setting and evaluating their own goals in order for goal setting programmes to remain effective over time.

Second, the students have developed a working schema of the goal setting process. All of the students know how to set, action and achieve goals, including planning how the goals will be achieved and identifying possible barriers. When goals are not attained, they are able to review possible reasons for the failure and engage in effective strategies to make the goal more achievable. The students cited lack of effort, the wrong attitude or an unrealistic goal as the most common causes for not achieving their goals. These attributions usually resulted in a resolve to try harder or to modify goals to make them more attainable, which is consistent with Pintrich and Schunk's (2002) view that the ability to attribute failure to controllable factors can result in increased effort in the future. The students' ability to reflect on their goals indicates that they are learning to take increased "responsibility for their own learning" (Ministry of Education, 1993, p. 7), therefore developing into self-regulated learners (Paris \& Paris, 2001). 
Finally, the way in which the school has implemented the goal setting programme (with the aim of helping students focus on their learning) has strongly contributed to the students' positive perceptions. Throughout the interviews with the Principal, Teachers and students, there was an obvious emphasis on using goal setting as a mastery approach to learning. The students never referred to goal setting as a means of outperforming others, but rather a way of improving their own learning or behaviour. In addition, the students appeared to have a high level of commitment to achieving their personal goals as indicated by their enthusiasm and acceptance that the purpose of setting goals was to achieve them. These findings lend support to Ames' (1992) assertion that classroom context powerfully affects students' goal orientations, and Ridley, McCombs and Taylors' (1994, cited in Eggen \& Kauchak, 2001) claim that goal commitment is increased when students are guided in setting their own goals.

Other ways in which the school helped students develop positive perceptions of goal setting as a tool for learning include extensive modeling of the goal setting process and adapting how it is used to suit the ages of the students.

Comments from the students and their teachers support the findings in the literature that goal setting is an important motivational process (Bandura, 1988, 1997; Schunk, 1989a, cited in Pintrich \& Schunk, 2002). Though students were not directly asked whether they felt goal setting increased their motivation, the results indicate that it did. The key to this motivation appears to come from the autonomy students have in setting their own goals in cases where the Teacher sets it, the rationale for the goal is given which corroborates findings made by Latham, Erez and Locke (1988, cited in Locke \& Latham, 2003).

Goal setting has a vital role to play in today's classrooms. It has positive links to motivation and self-regulation, two key components of effective thinking and learning. However, goal setting may not come naturally to all learners. The skills involved may need to be explicitly taught. This study has demonstrated that goal setting can be successfully taught to primary age students. For Teachers and Principals who are thinking about developing a goal setting programme, the following recommendations are suggested.

1. Use individual goal setting books so students can record their goals throughout the year.

2. Help students choose goals by making use of displayed learning intentions and encouraging students to write ideas down for future use.

3. Allow students to have ownership of their goals by allowing them to choose their own and ensuring they are involved in evaluating achievement of their goals.

4. Ensure that students set measurable goals. This will involve taking the time to teach the skills involved in setting, working towards, and monitoring goals.

5. Ensure that students set goals that are optimally challenging rather than too easy or difficult.

\section{REFERENCES}

Alderman, M.K. (2004). Motivation for achievement: Possibilities for teaching and learning. Mahwah, NJ: Lawrence Erlbaum Associates Inc.

Ames, C. (1992). Classrooms: Goals, structures, and student motivation. Journal of Educational Psychology, 84 (3), 261-271.

Berg, B. L. (2004). Qualitative research methods for the social sciences. Boston: Allyn \& Bacon.

Brophy, J. (2004). Motivating students to learn (2nd ed.). Mahwah, NJ: Lawrence Erlbaum Associates Inc.

Dweck, C.S. (1999). Self-theories: Their role in motivation, personality and development. Philidephia: Psychology Press.

Eggen, P. \& Kauchak, D. (2001). Educational psychology: Windows on classrooms (5th ed.) Upper Saddle River, NJ: Merrill Prentice Hall.

Locke, E. A. \& Latham, G. P. (1990). A theory of goal setting and task performance. New Jersey: Prentice Hall.

Locke, E.A. \& Latham, G. P. (2003). Building a practically useful theory of goal setting and task motivation: A 35 year odessey. American Psychologist, 57 (9), 705-717.

McMillan, J. H. \& Schumacher, S. (1997). Research in education: A conceptual introduction. (4th ed.). New York: Addison Wesley Longman, Inc.

Merriam, S. B. (1998). Qualitative research and case study applications in education. San Fransico: Jossey-Bass Inc.

Ministry of Education. (1993). New Zealand Curriculum Framework. Wellington: Learning Media.

Paris, S. G. \& Paris, A. H. (2001). Classroom applications of research on self-regulated learning. Educational Psychologist, 36 (2), 89-101.

Pintrich, P.R. (2000). The role of goal orientation in self-regulated learning. In M. Boekaerts. P.R. Pintrich, \& M. Zeidner (Eds.) Handbook of self-regulation. (pp. 451-502), San Diego: Academic Press.

Pintrich, P.R. \& Schunk, D.H. (2002). Motivation in education: Theory, research and applications (2nd ed.). Upper Saddle River, NJ: Prentice Hall.

Schunk, D. H. \& Zimmerman, B. J. (Eds.) (1998). Self-regulated learning: From teaching to reflective practice. New York: The Guildford Press.

Stipek, D. (2002). Motivation to learn: Integrating theory and practice (4th ed.). Boston: Allyn \& Bacon.

Walker Tileston, D. (2004). What every teacher should know about student motivation. Thousand Oaks, California: Corwin Press.

Zimmerman, B.J. (2002). Becoming a self-regulated learner: An overview. Theory into Practice, 41 (2), 64-70. 


\section{PROFILE OF AUTHOR}

Helga Grant is a qualified adult literacy tutor with Literacy Waikato and tutors primary and secondary students in English and Maths. She recently completed an Honours degree in Education at Massey University, specialising in educational psychology and literacy education. 